\title{
Exploration and Practice of Talent training mode under the Background of Applied transformation
}

\author{
Wei $\mathrm{Li}^{1, \mathrm{a}}$, Shuo Wang ${ }^{1, \mathrm{~b}}$ and Yang Yang ${ }^{1, \mathrm{c}}$ \\ 1Jilin Teachers'Institute of Engineering and Technology, Changchun,Jilin , China \\ a414388426@qq.com,,2235287419@qq.com,,2026835618@qq.com
}

\begin{abstract}
Keywords: Applied undergraduate; Double integrated talents training mode; Automobile service specialty
\end{abstract}

\begin{abstract}
This paper combines the training program of automobile service engineering specialty in Jilin engineering and technology Normal College, so as to determine the target of talent training. Research and development of teaching based on the concept of education and teaching, establish the application oriented curriculum system, practice teaching, construction planning theory teaching system, practice teaching platform of cooperation and enhance the comprehensive ability development link are proposed corresponding solutions and suggestions, aims to construct a "double integrated" training mode for Applied Research Cooperative Education talents.
\end{abstract}

"Higher education in Jilin province and long-term development plan" stressed, higher education should enhance the cultivation of applied talents, orientation training for applied undergraduate colleges should strengthen the cultivation of students' application ability, to guide local undergraduate colleges and universities in Jilin province high quality cultivation of applied talents, set up local universities in transition development alliance. Jilin Teachers Institute of engineering and technology has become the alliance chairman of the unit, automobile service engineering as one of the first schools in transition pilot professional, setting up an "integrated" collaborative research with education mode, one is relying on the real occupation situation, students into the enterprise. Two is the introduction of enterprises, technical personnel and projects into schools. From time to time to promote research cooperation to develop depth research, actively exploring open and mutual assistance with the new mode of cooperation, to build schools, enterprises and students between the "three party interaction, three party profit" open education mechanism, collaborative culture with innovative spirit and innovative talents of high-quality, high level application oriented talents.

\section{Adhere to local demand orientation and determine the target of personnel training}

Comprehensive job demand, the development trend of automotive service engineering, the demand for talents in Jilin's regional economy and many other factors. The automobile service engineering specialty has established the training and application type senior talents as an integrated, high-quality and applied talents oriented to the automobile service industry, including production, construction, management and service. This should make every effort to strengthen the ability of students to adapt to market development and related technical reform of automobile industry after training, vehicle engineering technology chain can keep pace with the longer life cycle of automobile performance research, performance testing and system defects, new models of new product design and development of the applied talents[1].

Based on the job assignment of professional post, the application course system is set up. After the car market, including automotive sales, maintenance, testing, auto insurance identification claims, as well as automobile trade organization, management, lease and lease, as well as the old car disposal and recycling, and a series of industrial value chain. Therefore, based on the analysis of the typical tasks of the industrial chain, the establishment of modular curriculum system in application for the purpose and characteristics, including the basis of professional learning module, sales and distribution module, financial and insurance module, repair and maintenance, second-hand car trading and other six modules. The theoretical teaching system is shown in Figure 1 below. 


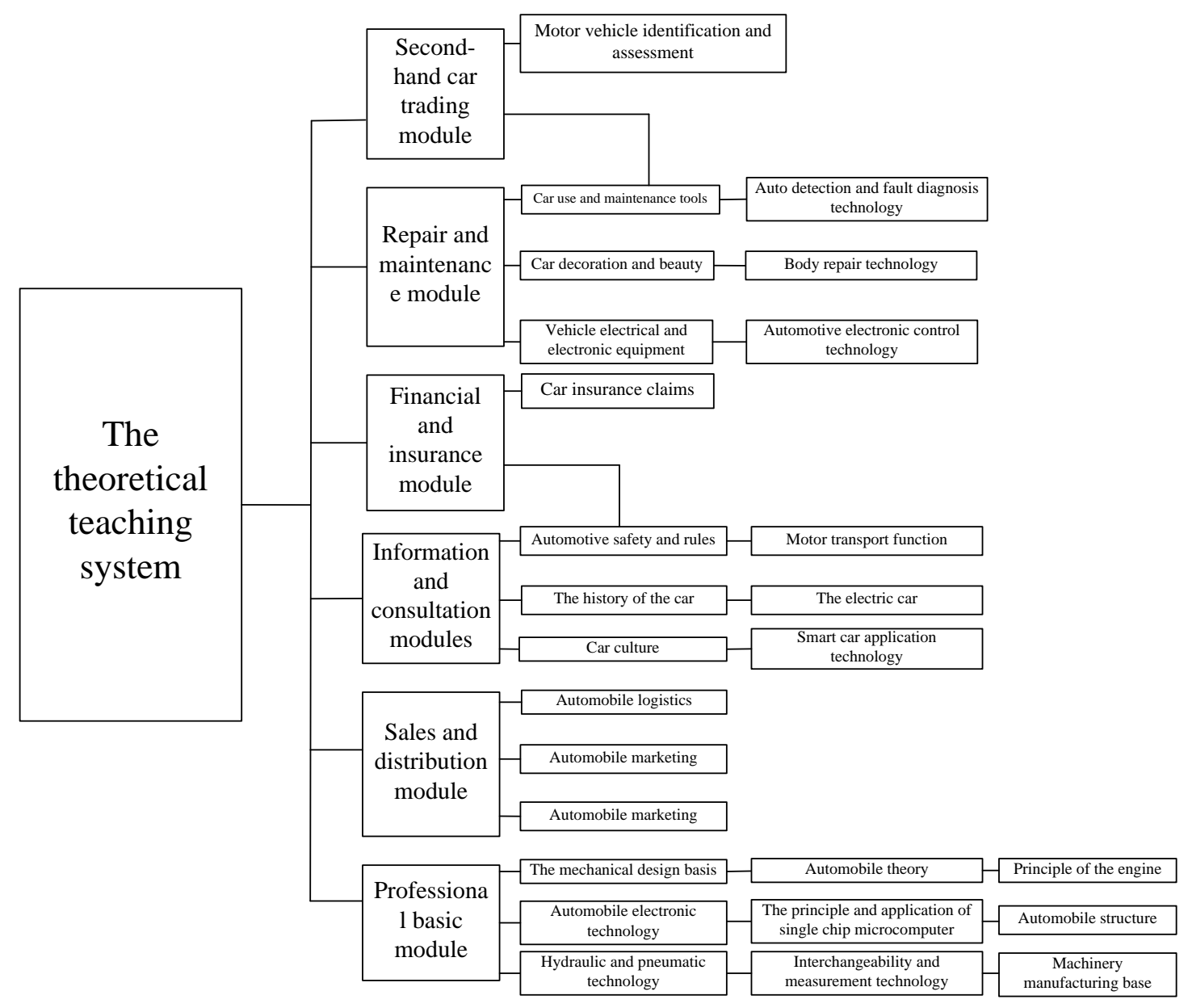

Figure 1. Theory teaching system

Take the post vocational skill as the instruction, constructs the practice teaching system. The advantage of training talents in automobile service engineering is that it is highly operational and practical. In order to meet the training requirements of integrated application of knowledge and key technical ability of post, the practical teaching system must be systematically designed. Based on the analysis of job occupation skills on [2], the building of the teaching system of applied practice, this system consists of four levels, the first level is the basic skill training is to improve the level of the second layer; the third layer is the layer of skill training; comprehensive training system; the fourth level is the science and technology innovation training. Between the four levels, from simple to complex, from single to integrated design ideas. 


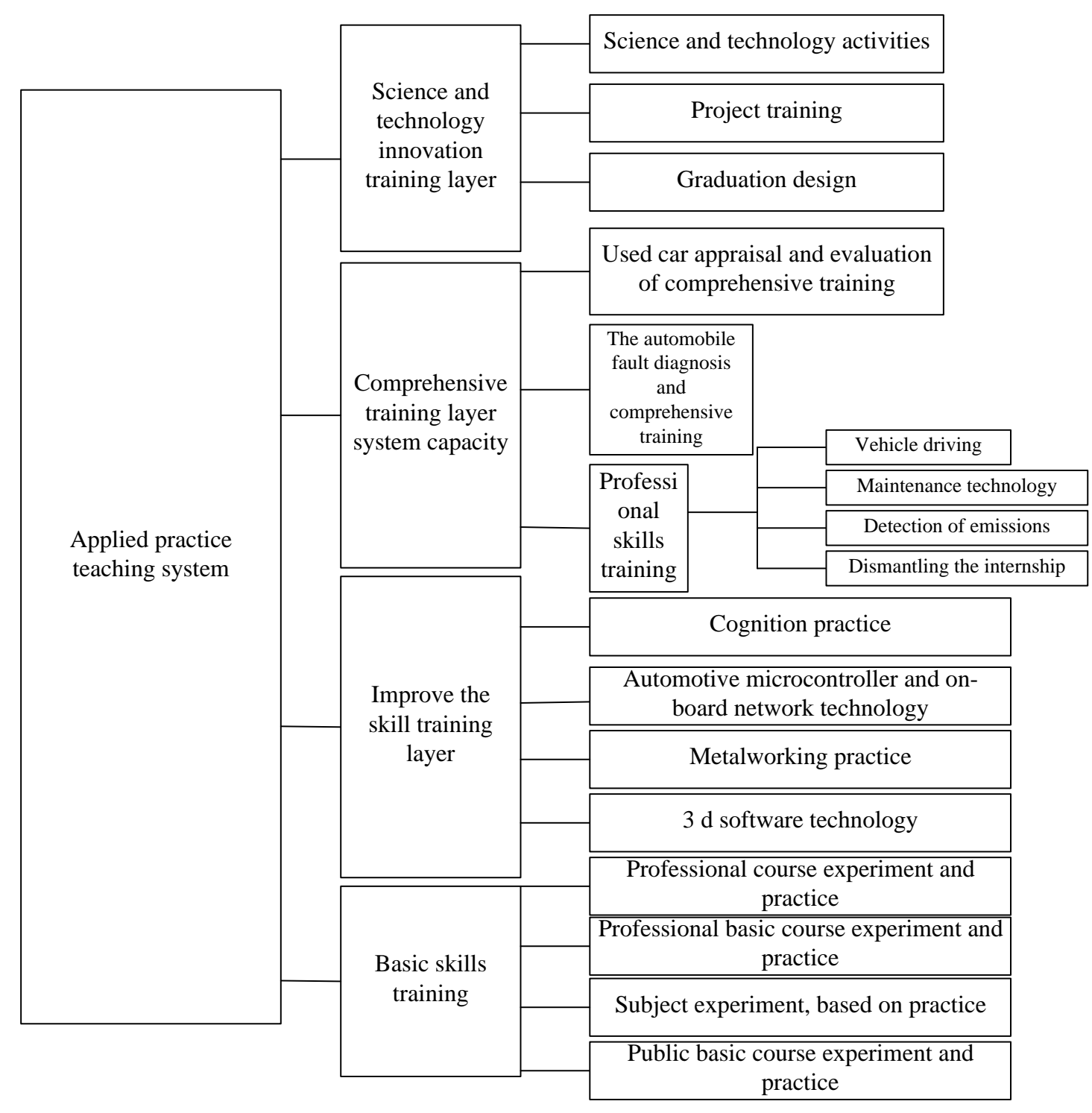

Figure 2.

Application oriented teaching system

\section{Personnel training, implementation of the path}

Enterprises should be urgent to build a short-term school enterprise curriculum replacement model. With the development of automobile industry, Automobile Expo attention gradually, the Chiheng Volkswagen 4S shop leaders made it clear that in every stage was held during the Expo, Chiheng Volkswagen 4S shop car needs a large number of professional talents. Take this opportunity, Jilin Teachers Institute of engineering and technology and Chiheng Volkswagen 4S shop signed a cooperation agreement, during the annual Auto Expo, Jilin Teachers Institute of engineering and technology courses to students will be replacement for learning, internship for a month in the post Chiheng Volkswagen 4S shop. Through the course of post replacement mode, so that the community, with the market, in cooperation with enterprises, a new concept of the combination of theory and practice, which not only improve the education and training of talents, but also conducive to the development of the enterprise.

Set up enterprise requirements - the establishment of automotive transmission system characteristic orders class. Order class refers to the cooperation between the students and the professional enterprises concerned and training personnel. After the student accepts the related training which the enterprise makes, passes through the examination, achieves enterprise's employment standard, after graduation may directly go to this enterprise to carry on the work. The order class adopts the "2+1" mode, that is, two years of study in the school, one year in the enterprise paid internship. The specific measures for the first grade and the second grade last 
semester in school culture courses and professional basic courses, the second grade second semester in school enterprise cooperation production practice factory internship for six months' internship summary in the first semester of the third grade problem, need to strengthen the skills, and then targeted at school professional learning, the third grade second semester internship factory of the first half of the post production. The school and enterprise jointly complete the teaching task, and the teaching process is completed by both the school and the enterprise. The school is responsible for strengthening the students' professional theory foundation, and the enterprise is responsible for improving the students' practical operation ability. Both schools and enterprises have the resources of teachers, and they interact and complement each other and combine with each other. We should cultivate high-quality application-oriented talents for the needs of enterprises and society.

The combination of teachers and engineers and the "double direction" of graduate design. In view of the graduation project of applied undergraduate students, we must collect the real situation of various aspects, and set up the topic as far as possible in the topic "application type", and pay attention to the practicability and teaching of the subject. Students can according to early in the enterprise internship experience through empirical summary, find problems, seek solutions, and then with the help of the teacher, set up their own graduation design topic, and in the guidance of teachers and the master of the enterprise, to complete the graduation design. To learn basic knowledge of university graduates, during a comprehensive summary of the application of professional knowledge with enterprise internship comprehensively, so as to facilitate the society become advanced talents, to lay a solid foundation for employment.

\section{Effectiveness of personnel training}

Promote enterprise technological innovation and product upgrading. In the process of school enterprise cooperation, the upgrading of enterprise science and technology products and technological innovation have been realized. Suzhou Zi Yu Electrical Appliance Co. Ltd. and Shenyang colorstone Technology Co. Ltd. and other companies are drones, and the air traffic control with unmanned aerial machine business, orders are expected to 200 units, started running and achieved good economic benefits.

Obtained the employer's affirmation and the social concern. Through the evaluation and feedback of employers tracking, most of the students employment in their work in calm and can achieve flexible application of professional knowledge of their own learning, and actively assigned tasks with high efficiency; pay attention to team spirit, positive and conscientious in the team; by employing social enterprises alike.

Practice has proved that the enterprises and universities in the process of school enterprise cooperation can stimulate the industry enterprises to increase investment in research to cultivate the positive cooperative innovation and talent, and make full use of scientific and reasonable management mode and practical technology, advanced enterprise project to provide strong technical support and project support for the school, out of a "production" the direction of the "learning" as the basis, to "research" as a link to "use" the road [4] applied talents training destination. We hope to further strengthen cooperation with enterprises through the cooperative relations of "industry, University, research and research", and make breakthroughs in the combination of production, research and research, and realize win-win cooperation between universities and employers".

\section{Acknowledgements}

Wei Li (1980-), female, Liaoning Dalian people, Jilin engineering teachers college, experimental division; Jilin Province Education Science "12th Five-Year" plan project (item number: ZD15118), host: Wei Li

\section{References}

[1]W. Huang, Research on Teaching Reform of Talents Training in Automotive Service Engineering 
in Applied University, 2014.

[2]Y.Q. Yang, Exploration and Practice of Practical Teaching System for Applied Personnel Training, 2014.

[3]Z.W. Li, Optimizing the Training Mode of Tourism Professionals, 2014.

[4]Z.P. Wan, Research on the Hierarchical Training System of Innovative and Applied Talents in Internet of Things, 2013.

[5]Yu Dongsheng. Evaluate the first-class undergraduate education: path and value, the experience and significance $[\mathrm{J}]$. Journal of higher engineering education research. 2012 (3)

[6]Wang Yufeng. The rise of the newly built undergraduate course colleges and universities of China, the predicament and outlet [J]. Journal of higher education research, 2011 (01)

[7]Sun Qin jian-guo xia. Literature review about the technical undergraduate education research [J]. vocational education BBS. 2014 (13)

[8]Flush, jia-yong zhu. Applied undergraduate colleges and universities personnel training goal and its implementation of strategies [J]. Journal of higher education BBS. 2010 (6)

[9]Summer, wu yue-hong xu. Generation logic and value implication of the applied university league - based on the analysis of the transformation of ordinary undergraduate course colleges and universities development perspective [J]. Journal of modern university education. 2015 (6)

[10]Wang sj, jing-wen wen, Hu Dan. Social transformation and applied colleges thinking of the construction of the modern university system [J]. Modern education management. 2015 (7) 